Revista de

Contabilidade e

Organizações

www.rco.usp.br
DOI: http://dx.doi.org/10.11606/rco.v10i28.117375
Journal of

Accounting and

Organizations

\title{
Uso das alavancas de controle de Simons (1995) na gestão de uma cooperativa agroindustrial
}

\author{
Caroline Sulzbach Pletscha; Carlos Eduardo Facin Lavarda ${ }^{\mathrm{b}}$ \\ ${ }^{a}$ Universidade do Estado de Santa Catarina \\ ${ }^{b}$ Universidade Federal de Santa Catarina
}

\section{Informações do Artigo}

Histórico do Artigo

Recebido: 05 de julho de 2016

Aceito: 07 de dezembro de 2016

Palavras chave:

Alavancas de Controle.

Sistemas de Controle Gerencial.

Cooperativa Agroindustrial.

\begin{abstract}
Resumo
O estudo teve como objetivo verificar como as alavancas de controle de Simons (1995) são utilizadas na gestão de uma Cooperativa Agroindustrial. Trata-se de um estudo de caso em uma Cooperativa Agroindustrial, com característica descritiva e qualitativa. Para a coleta de dados se utilizou de entrevistas, documentos e observação. Foi utilizado a análise de conteúdo categorizada por temas, com o auxílio do software Nvivo ${ }^{\circledR}$ e nuvens de palavras para a análise dos dados. Verificou-se que sistemas de diagnóstico (monitoramento das atividades) e sistemas interativos (envolvimento dos gestores, incentivo a aprendizagem organizacional e o surgimento de novas ideias) são os de maior utilização na organização, pois estes são utilizados constantemente e fazem parte do dia a dia da organização objeto do estudo. As crenças não são disseminadas de forma clara e os sistemas de fronteiras são utilizados somente quando existe a necessidade de se estabelecer limites de atuação e comportamentais, não sendo utilizados constantemente.
\end{abstract}

Copyright (C) 2016 FEA-RP/USP. Todos os direitos reservados

\section{INTRODUÇÃO}

As cooperativas do ramo agropecuário, que geralmente cuidam de toda a cadeia produtiva, desde o preparo da terra até a industrialização e comercialização dos produtos, formam atualmente o segmento econômico mais forte do cooperativismo brasileiro. Também são um dos ramos com maior número de cooperativas e cooperados no Brasil (OCB, 2015).

Para permanecerem nesta situação exposta, as cooperativas necessitam de sistemas de controle que possibilitem uma gestão eficaz (ISIDORO et al., 2012), bem como adaptar seus controles às pressões do ambiente. Segundo Bialoskorski Neto, Nagano e Moraes (2006), as cooperativas precisam de processos eficientes de controle e monitoramento, por serem uma forma de constituição em que os associados possuem uma parcela de direitos de propriedade e de decisão. Também possuem uma crescente importância no mercado nacional e mundial (ISIDORO et al., 2012).

O processo de controle é uma característica central de todas as organizações, sendo uma parte fundamental da atividade organizacional, o qual inclui a adaptação da organização diante de novas situações, levando em consideração seus objetivos e propósitos. Nesse sentido, o controle tem sido identificado como o processo para garantir que a organização está adaptada às mudanças externas e internas e está desenvolvendo ações para alcançar seus objetivos (OTLEY; BERRY, 1980).

Desta forma, controles gerenciais podem ser utilizados de diferentes formas nas organizações. De acordo com Simons (1995), podem ser utilizados como sistemas de crenças, diagnóstico, interativo e fronteira. Estas quatro alavancas de controle, segundo Nisiyama e Oyadomari (2012, p. 106), "possibilitam melhor entendimento da aplicação dos controles gerenciais".

Autor Correspondente: Tel (48) 37219383

E-mail: carol_spletsch@yahoo.com.br(C.S. Pletsch); elavarda@gmail.com (C. E. F. Lavarda)

Universidade Federal de Santa Catarina, Departamento de Ciências Contábeis. - Trindade - CEP 88040900 - Florianópolis, SC - Brasil. 
Conforme o modelo de alavancas de controle de Simons (1995), os sistemas de crenças são utilizados para inspirar e direcionar a busca de oportunidades. Sistemas de fronteiras são utilizados para estabelecer limites ao comportamento dos participantes da organização. Já os sistemas de controle de diagnóstico são utilizados para motivar, monitorar e recompensar o alcance de metas. Por fim, os sistemas de controle interativo são usados para estimular o debate de premissas e planos e permitir o surgimento de novas ideias e estratégias.

Neste contexto, tem-se o seguinte problema de pesquisa que norteia o presente estudo: Como as alavancas de controle de Simons (1995) são utilizadas na gestão de uma Cooperativa Agroindustrial? Para responder à questão problema, o estudo busca verificar como as alavancas de controle de Simons (1995) são utilizadas na gestão de uma Cooperativa Agroindustrial, já que na literatura há escassez de evidências nestas organizações.

Estudos nacionais e internacionais utilizaram-se das alavancas de controle de Simons (1995) em diferentes aspectos: relações entre o uso de Sistemas de Controle Gerencial (SCG) e capacidades organizacionais (HENRI, 2006; OYADOMARI 2008), alinhamento dos controles de custo e estratégia, utilizando o modelo das alavancas de controle (DIEHL, 2006), utilização das alavancas de controle de Simons para explorar os antecedentes de sistemas de controle (WIDENER, 2007), contribuição dos SCG para a formação e implementação da estratégia organizacional (ALVES, 2010), o uso interativo e de diagnóstico dos SCG nas diferentes fases do ciclo de vida organizacional (LAVARDA; PEREIRA, 2012), equilíbrio do papel tradicional de controle e do papel inovador dos SCG (ZHENG, 2012), relação entre estilo de liderança, definição de uso do SCG e inovação tecnológica (CRUZ, 2014), estilo de liderança como um antecedente da definição de uso do sistema de controle gerencial (CRUZ, FREZATTI, BIDO, 2015) e relação entre uma cultura flexível e as alavancas de controle (HEINICKE, GUENTHER, WIDENER, 2016).

A motivação para a realização deste estudo decorre da escassez de evidências empíricas no Brasil sobre o uso do Sistema de Controle Gerencial (AGUIAR; FREZATTI, 2007; OYADOMARI, 2008), bem como o modelo de alavancas de controle de Simons (OYADOMARI, 2008). Além disso, este estudo difere-se dos demais por abordar os Sistemas de Controle Gerencial no âmbito de uma Cooperativa Agroindustrial. O desenvolvimento do estudo em uma cooperativa representa um diferencial, pois há especificidades em seus controles e acompanhamentos que podem ser diferentes daqueles utilizados por organizações empresariais.

Tem-se como contribuição teórica do estudo o entendimento do uso das alavancas de controle em uma Cooperativa Agroindustrial que possui controles gerenciais formalizados. Torna-se importante ter esse entendimento, visto que as alavancas de controle precisam ser utilizadas em equilíbrio, ou seja, ao mesmo tempo que permitem inovação e contribuição com novas ideias, tem-se o monitoramento e controle das atividades. No campo prático e social, contribui ao propiciar informações relevantes para o processo de gestão, tendo em vista a continuidade dos negócios. O estudo também contribui ao visualizar na prática as alavancas de controle.

\section{REFERENCIAL TEÓRICO}

No referencial teórico deste estudo é apresentado uma abordagem conceitual das alavancas de controle de Simons (1995) e estudos anteriores que auxiliam na análise dos dados.

\subsection{Alavancas de Controle}

Simons (1995), por meio de diversos estudos de casos, desenvolveu o modelo de alavancas de controle, que consiste em quatro tipos de controle (crenças, fronteira, diagnóstico e interativo).

Sistemas de crenças são um conjunto de definições organizacionais que são comunicados formalmente pelos gestores, para prover valores básicos, propósitos e direção para a organização. Os valores básicos, missões e propósitos são relacionados com a estratégia da empresa e podem ser considerados parte de um sistema quando estes são formais, baseado em informações e usado pelos gestores para manter ou alterar os padrões das atividades da organização (SIMONS, 1995).

Sistemas de crenças informam os valores da organização, com a finalidade de inspirar e motivar os funcionários para pesquisar, criar, inovar, buscar oportunidades (WIDENER, 2007) e podem ser usados como 
mecanismo de mudança estratégica (MARGINSON, 2002).

Sistemas de fronteiras consistem em regras que estabelecem limites ao comportamento dos membros da organização (SIMONS, 1995). Os sistemas de fronteiras impõem limites de atuação da organização, garantindo que as estratégias realizadas estejam dentro do domínio das atividades organizacionais (SIMONS, 2000). Também são usados para definir limites comportamentais, na busca de oportunidades e inovação (BRUINING; BONNET; WRIGHT, 2004). Sistemas de fronteiras estabelecem limites por meio de regras, códigos de conduta, sistemas de planejamento estratégico e diretrizes, os quais são influenciados pelos riscos que se propõe a evitar (COLLIER, 2005).

Os sistemas de diagnóstico são considerados sistemas de feedback, para garantir a realização dos objetivos organizacionais. São sistemas formais utilizados pelos gestores para monitorar resultados e corrigir desvios de desempenho. Sistemas de controle de diagnóstico possuem a habilidade de mensurar as saídas dos processos, corrigir os desvios de desempenho e comparar padrões pré-determinados com resultados atuais (SIMONS, 1995). Por meio do uso de controles de diagnóstico é possível analisar os fatores que permitem que as estratégias pretendidas sejam alcançadas (HENRI, 2006).

Os sistemas de controle são considerados interativos quando os gestores os utilizam de forma regular e frequente tanto para si, quanto para os funcionários (SIMONS, 1991). São operados subjetiva e informalmente, por meio de experiências, percepções, discussões (DIEHL, 2006), diálogos frequentes (HENRI, 2006, WIDENER, 2007), reuniões regulares, revisão de planos de ação (SIMONS, 1991), o que estimula a pesquisa, aprendizagem organizacional (LANGFIELD-SMITH, 1997; BRUINING; BONNET; WRIGHT, 2004) e desenvolvimento de novas ideias (LANGFIELD-SMITH, 1997; BRUINING; BONNET; WRIGHT, 2004; HENRI, 2006), Sistemas de controle interativo contribuem para a inovação (BISBE; OTLEY, 2004) e busca de novas estratégias em um mercado dinâmico (BRUINING; BONNET; WRIGHT, 2004; WIDENER, 2007). Assim, os gestores asseguram que a organização terá respostas as ameaças do ambiente, bem como aproveitará as oportunidades que surgirão (SIMONS, 1990).

Quatro conceitos estão relacionados as alavancas de controle e são controlados por elas, sendo estes: valores fundamentais, riscos a serem evitados, variáveis críticas de desempenho e incertezas estratégicas. Os sistemas de crenças orientam o processo criativo e inspiram a busca de novas oportunidades, controlando os valores fundamentais. Os sistemas de fronteiras, que limitam o comportamento dos participantes da organização, controlam os riscos a serem evitados. Sistemas de controle de diagnóstico que possuem a função de monitorar, avaliar e recompensar a realização de metas, controlam as variáveis críticas de desempenho. Já os sistemas de controle interativo, que possuem a função de estimular a aprendizagem organizacional e o processo de desenvolvimento de novas ideias e estratégias, controlam as incertezas estratégicas (SIMONS, 1995).

Frente a revisão da literatura sobre o modelo de alavancas de controle de Simons (1995), pode-se considerar que em uma organização, cada alavanca de controle pode ser utilizada de diferentes maneiras, seja especificamente na forma de controlar suas atividades ou no equilíbrio das tensões dinâmicas. Depende de como a organização gerencia seus negócios, em busca de seus objetivos. Segundo Kruis, Speklé e Widener (2016), vários estudos serão necessários para proporcionar uma compreensão conclusiva do equilíbrio das alavancas de controle.

\subsection{Estudos anteriores}

Os estudos anteriores abordados se referem aqueles que utilizaram as alavancas de controle de Simons (1995), os quais contribuem para a análise dos dados do presente estudo.

Bonner, Ruekert e Walker (2002) examinaram os mecanismos de controle formais e interativos disponíveis para gestores no controle de projetos de desenvolvimento de novos produtos, bem como a relação desses mecanismos de controle com o desempenho. Para a realização do estudo foi aplicado questionário para os profissionais que trabalham no desenvolvimento de produto, os quais são membros da Associação Americana de Marketing. A amostra foi composta por 95 questionários respondidos. Os resultados sugerem que o potencial criativo no desenvolvimento de produtos é utilizado plenamente quando há flexibilidade na atividade desempenhada, ou seja, controles excessivos podem limitar a criatividade da equipe, interferindo no desempenho final.

Diehl (2006) realizou um estudo de caso em uma organização prestadora de serviços na área de segurança, em que analisou o alinhamento dos controles de custo e estratégia, utilizando o modelo das alavancas de controle. Constatou que o controle estratégico de custos pode ser considerado como apoio a estratégia, o que contribui para 
melhor desempenho e maior efetividade estratégica; a empresa não possui formalização das crenças; o sistema de fronteira é vinculado as questões de legislação, ética junto aos clientes e limites estratégicos; o controle diagnóstico é o mais frágil da empresa, em que as ações são tomadas de forma reativa; o sistema de controle interativo é bem desenvolvido. Evidenciou um desequilíbrio na utilização das alavancas de controle, em que sistema de crenças e sistema de controle interativo são mais valorizados que os demais.

Oyadomari (2008) averiguou a existência, identificou e qualificou os relacionamentos entre o uso de SCG e as competências organizacionais. Para a realização do estudo foi aplicado um questionário em 104 empresas das 1000 maiores empresas brasileiras que constam na Revista Exame - Edição Melhores e Maiores de 2008. Os resultados indicaram que o uso de sistemas de diagnóstico é importante para a gestão da organização e a comparação de metas com os resultados alcançados não desestimula as competências organizacionais; o uso interativo está relacionado positivamente com as competências organizacionais. Alves (2010) realizou um estudo de caso em uma instituição de ensino superior, sem fins lucrativos, para identificar a contribuição dos SCG para a formação e implementação da estratégia organizacional. A coleta de dados deu-se por meio de entrevistas, análise de documentos e observação. Os resultados demonstraram que há interdependência entre os diferentes SCG da organização e que sistemas de crenças influenciam no clima estratégico da organização. Além disso, foi constatado que, sistemas de crenças influenciam o uso diagnóstico, interativo e de fronteira dos SCG.

Vasconcelos (2012) realizou um estudo em uma amostra de pequenas e médias empresas portuguesas do setor tecnológico em que evidenciou os papéis dos Sistemas de Controle Gerencial, de acordo com o modelo de alavancas de controle de Simons (1995). Os resultados demonstraram que os sistemas de planejamento financeiro, avaliação financeira e controle de custos são utilizados na forma de diagnóstico; valores e missão são utilizados como sistema de crenças; gestão de desenvolvimento de novos produtos ocorre de forma interativa. Ainda constatou que quanto mais dinâmico for o ambiente e mais orgânica for a estrutura, sistemas de diagnóstico e interativo são utilizados em conjunto; quanto mais as tarefas forem incertas e maior a hostilidade do ambiente, menor é o uso de sistemas de controle de diagnóstico.

Cruz (2014) em um estudo com 164 empresas, a maioria de grande porte, investigou a relação entre estilo de liderança, definição de uso do SCG e inovação tecnológica. Constatou que sistemas de crenças, interativo e de fronteira influenciam positivamente a inovação tecnológica. Empresas que buscam inovar em produtos e processos devem investir na comunicação de valores e objetivos relacionados a inovação, em discussões entre diferentes áreas e membros, no estabelecimento de limites para a ação dos funcionários, fornecendo foco para que as ações sejam desenvolvidas.

Cruz, Frezatti e Bido (2015) desenvolveram um estudo que buscou explorar o estilo de liderança como um antecedente da definição de uso do sistema de controle gerencial. Para tanto, realizaram um levantamento com 164 empresas. Evidenciaram como um antecedente do uso interativo e do sistema de crenças, a liderança transformacional. Sistemas de crenças, interativo e fronteiras influenciam positivamente na inovação tecnológica.

Heinicke, Guenther e Widener (2016) examinaram a relação entre uma cultura flexível e as alavancas de controle. A amostra compreendeu 267 gerentes de médias empresas. Os resultados demonstraram que quanto mais as empresas enfatizam uma cultura flexível, mais enfatizam o uso de sistemas de crenças. Neste caso, sistemas de crenças representam um importante mecanismo de controle em organizações que possuem foco em uma cultura flexível.

O objetivo do estudo de Kruis, Speklé e Widener (2016) foi examinar os padrões de uso das alavancas de controle. Foram obtidas respostas de 217 gestores. Constataram uma solução estável composta por quatro padrões de controle, como manifestação de equilíbrio.

\section{PROCEDIMENTOS METODOLÓGICOS}

A pesquisa caracteriza-se como descritiva, estudo de caso e qualitativa. O objeto de estudo compreendeu uma Cooperativa Agroindustrial, com várias unidades de negócios espalhadas pelo Brasil e com aproximadamente 1.600 funcionários. A mais de 40 anos, vários agricultores se reuniram para constituir a cooperativa devido as dificuldades de armazenamento e transporte de grãos. A cooperativa foi expandindo suas atividades e atualmente abrange prestação de serviços, no que tange ao recebimento, beneficiamento, armazenagem e comercialização de grãos, serviços de transporte, assistência técnica agronômica, comercialização de insumos, máquinas, implementos 
e ferramentas. Trabalha na área industrial com aves e rações e possui alguns supermercados.

O estudo de caso foi desenvolvido nesta organização, pelo fato de possuir controles gerenciais formalizados, o que contribui para a consecução deste estudo, ao revelar o processo de gestão. Para a coleta de dados se utilizou de entrevistas, documentos e observação.

Utilizou-se de um roteiro de entrevista semiestruturado com questões abertas, construídas a partir do marco teórico e de instrumentos já utilizados em outras pesquisas. O instrumento de pesquisa composto por quatro blocos e 27 questões faz parte de uma dissertação de mestrado, sendo que neste estudo apresenta-se os resultados do terceiro bloco do instrumento de pesquisa. As questões que compõe o terceiro bloco foram utilizadas e adaptadas do instrumento de pesquisa do estudo de Alves (2010), o qual teve como base a obra de Simons (1995, 2000).

Para validar o instrumento de pesquisa, foi realizado um pré-teste. Inicialmente foi entregue o roteiro de entrevista para um professor e três alunos a fim de verificar a adequação e clareza das questões, bem como sugestões de melhorias. Após as alterações sugeridas, foi realizada a entrevista com um gestor de uma construtora de imóveis. A entrevista piloto foi gravada, transcrita e analisada, a fim de verificar se as questões atendem aos objetivos do estudo.

As entrevistas foram realizadas com o Diretor Vice-Presidente, Diretor Secretário, Diretor Adjunto, Gerente Técnico/Industrial, Gerente Administrativo/Financeiro, Gerente Comercial, Gerente Operacional e três Gerentes de Entrepostos, sendo gravadas e transcritas na íntegra, no mês de novembro de 2014. As entrevistas foram realizadas nas dependências da organização objeto do estudo. Duas foram realizadas por skipe, pois tratavase de dois gerentes que trabalham em entrepostos distantes da matriz, onde foram realizadas as demais entrevistas. As entrevistas foram gravadas, transcritas e tiveram uma duração média de 50 minutos.

Os documentos consultados no estudo foram o relatório anual, site da empresa, demonstrações financeiras e notas explicativas. A observação foi realizada de forma não-estruturada. Segundo Alves-Mazzotti e Gewandsznajder (1999), na observação não-estruturada, as situações são observadas da forma que ocorrem, sem haver uma definição prévia do que será observado. As observações ocorreram nos dois dias em que as entrevistas foram realizadas. No Quadro 1 apresenta-se o constructo do estudo.

\begin{tabular}{|c|c|c|c|}
\hline Categorias & Sub Categorias & Questões & Autores \\
\hline \multirow{2}{*}{ Crença } & Valores & $\begin{array}{l}\text { Como são transmitidos os valores } \\
\text { organizacionais aos subordinados? }\end{array}$ & \\
\hline & Propósitos & $\begin{array}{l}\text { Como são transmitidos os propósitos gerais da } \\
\text { organização aos subordinados? }\end{array}$ & \\
\hline \multirow[t]{2}{*}{ Fronteira } & Limites de atuação & $\begin{array}{l}\text { Como são estabelecidos os limites de atuação } \\
\text { da organização, garantindo que as estratégias } \\
\text { realizadas estejam dentro do domínio das } \\
\text { atividades organizacionais (atividades, } \\
\text { mercados, riscos)? }\end{array}$ & Simons $(1995,2000)$ \\
\hline & $\begin{array}{l}\text { Limites } \\
\text { comportamentais }\end{array}$ & $\begin{array}{l}\text { Como são estabelecidos os limites para guiar o } \\
\text { comportamento dos indivíduos na organização? }\end{array}$ & $\begin{array}{l}\text { Bruining, Bonnet e Wright } \\
\text { (2004), Collier (2005), }\end{array}$ \\
\hline \multirow{2}{*}{ Diagnóstico } & Monitoramento & $\begin{array}{l}\text { Como é monitorada a realização de planos e } \\
\text { metas? }\end{array}$ & $\begin{array}{l}\text { Widener (2007), Alves } \\
\text { (2010), Oliveira (2012) }\end{array}$ \\
\hline & Recompensa & $\begin{array}{l}\text { Como é recompensada a realização de planos } \\
\text { e metas? }\end{array}$ & \\
\hline \multirow{2}{*}{ Interativo } & $\begin{array}{l}\text { Envolvimento dos } \\
\text { gestores }\end{array}$ & $\begin{array}{l}\text { Como os gestores se envolvem regularmente } \\
\text { e pessoalmente nas atividades de decisão dos } \\
\text { subordinados? }\end{array}$ & \\
\hline & $\begin{array}{l}\text { Aprendizagem } \\
\text { organizacional }\end{array}$ & $\begin{array}{l}\text { Como é estimulada a aprendizagem } \\
\text { organizacional e a manifestação de novas } \\
\text { ideias? }\end{array}$ & \\
\hline
\end{tabular}

Quadro 1. Constructo do estudo

Fonte: Dados da pesquisa. 
As transcrições das entrevistas, documentos e observações constituíram um relatório de campo, contendo e-mails enviados e recebidos da empresa, protocolo do estudo assinado pelos entrevistados, e-mails dos sujeitos da pesquisa de aprovação das entrevistas transcritas, resumo das codificações, documentos e anotações das observações. Para a análise dos dados, utilizou-se da técnica análise de conteúdo, categorizada conforme itens apresentados no Quadro 1, com o auxílio do software $\mathrm{Nvivo}^{\circledR}$ e das nuvens de palavras construídas por meio do aplicativo Wordle.

\section{DESCRIÇÃO E ANÁLISE DOS RESULTADOS}

O modelo de alavancas de controle de Simons (1995) é constituído por quatro tipos de controle, os sistemas de crenças, sistemas de fronteiras, sistemas de diagnóstico e sistemas interativos. No Quadro 2 visualizamse as considerações dos sujeitos da pesquisa sobre os sistemas de crenças, ao serem questionados sobre como são transmitidos os valores e propósitos gerais da organização aos subordinados.

\begin{tabular}{|c|c|}
\hline $\begin{array}{c}\text { Sujeito da } \\
\text { Pesquisa }\end{array}$ & Considerações dos sujeitos da pesquisa sobre os sistemas de crenças \\
\hline Sujeito 1 & "Tudo por sistema". \\
\hline Sujeito 2 & "Hoje não está tanto em evidência como em outros tempos, mas por meio de cartazes, e-mail, reuniões". \\
\hline Sujeito 3 & "É a parte de RH que faz isso também, missão, propósito, nesse sentido". \\
\hline Sujeito 4 & $\begin{array}{l}\text { "Nós fizemos reuniões, nós fizemos algumas alterações na nossa visão, missão, valores e políticas da } \\
\text { qualidade, adaptando ela ao BRC, isso tem que ser divulgado, por que é um dos pontos que a própria BRC } \\
\text { cobra, eles fazem perguntas individuais aos funcionários. Então isso é muito divulgado, jornalzinho". }\end{array}$ \\
\hline Sujeito 5 & $\begin{array}{l}\text { "Todos sabem onde a cooperativa quer chegar. No próprio PLR isto está explícito. Nós temos a missão, } \\
\text { visão, valores, mas acredito que nem todos saibam. A grande maioria acho que nem sabe. Nessa parte } \\
\text { estamos um pouco falhos, mas o que a gente trabalha é em cima de atividades mesmo e o que a gente } \\
\text { repassa para os colaboradores, para os gerentes, são as metas que queremos atingir, a oportunidade que tem } \\
\text { de crescer". }\end{array}$ \\
\hline Sujeito 6 & $\begin{array}{l}\text { "Tem, tem, mas eu diria assim, a gente não perde muito tempo na área comercial em cima disso, a área } \\
\text { comercial é comprar da melhor forma possível, no momento certo, o melhor preço, ter todos os produtos } \\
\text { que o produtor precisa, para que não tenha que ir num outro lugar buscar o que ele precisa". }\end{array}$ \\
\hline Sujeito 7 & "Através de reuniões, através de instruções, de sistemas, você passa isso ai". \\
\hline Sujeito 8 & $\begin{array}{l}\text { "Através de correio eletrônico, através de instrução normativa principalmente. Cada gerente absorve as } \\
\text { normativas e repassa aos colaboradores através de reuniões, treinamentos". }\end{array}$ \\
\hline Sujeito 9 & $\begin{array}{l}\text { "Hoje tem muito treinamento e nesses treinamentos sempre tem alguém presente da empresa que faz a } \\
\text { abertura, dá início, ou muitos treinamentos é feito por funcionários da empresa que colocam isso para os } \\
\text { funcionários. E também no entreposto, nas conversas que a gente tem, nas reuniões que a gente faz com os } \\
\text { funcionários é colocado isso tudo". }\end{array}$ \\
\hline Sujeito 10 & $\begin{array}{l}\text { "Geralmente a gente leva para treinamento [...]". "A maioria não conhece. Entra de um lado e sai do outro, } \\
\text { eles não assimilam muito". }\end{array}$ \\
\hline
\end{tabular}

Quadro 2. Síntese dos relatos sobre os sistemas de crenças

Fonte: Dados da pesquisa

A cooperativa possui missão, visão e valores, os quais são demonstrados no site da organização. Os valores e propósitos são repassados para os membros da organização por meio de reuniões, treinamentos, instruções normativas, correio eletrônico, jornais e pela área de Recursos Humanos no momento da contratação. $\mathrm{Na}$ indústria de aves principalmente, devido as exigências da British Retail Consortium (BRC) que refere-se a padrões estabelecidos de segurança alimentar, os valores e propósitos tem maior divulgação. 
Na cooperativa em geral, verifica-se no relato dos Sujeitos 2, 5 e 10, apresentados no Quadro 2, que a maioria dos funcionários não tem conhecimento dos valores e propósitos, e por mais que sejam repassados, não assimilam estas informações. O Sujeito 5 relata que a cooperativa está um pouco falha nisto, porém se detém nas atividades, repassando as oportunidades de crescimento, desafios, ações e as metas a serem atingidas.

No relatório anual, a empresa apresenta as metas para o ano seguinte, desde metas de faturamento, como investimentos, aquisições e melhorias a serem realizadas, a expansão das suas atividades, treinamentos e cursos para colaboradores e cooperados. Juntamente com as metas, apresenta seu planejamento, orçamento, faturamento, custos, despesas e a mensuração de resultados, para que seus objetivos sejam alcançados.

Com base nas informações repassadas aos colaboradores sobre as ações e metas da empresa, as quais constam no relatório anual, pode-se inferir que estas estão relacionadas com a missão, visão e valores, que são divulgados no site da empresa. Estes resultados vão ao encontro do estudo de Alves (2010), que evidenciou a utilização de controles relacionados a estrutura de governança e a valores. Na estrutura de governança, considerou as reuniões realizadas para transmissão dos valores e propósitos e nos controles relacionados a valores, abrangeu os objetivos organizacionais, procurando relacionar com a visão, missão e valores. Também corrobora o estudo de Vasconcelos (2012), em que valores e missão foram utilizados como sistema de crenças.

Alguns gestores percebem que por mais que a organização possua suas crenças evidenciadas, os colaboradores não possuem conhecimento das mesmas. Enquanto que para outros gestores, as crenças se demonstram claras para todos os membros da organização.

As evidências sugerem que as crenças não são disseminadas de forma clara em toda a organização, necessitando ser melhorada. Isto estimula a realização de novos estudos, com o intuito de compreender como ocorre a utilização dos sistemas de crenças em outras empresas, bem como identificar se estes encontram-se institucionalizados. Diante desta constatação, pode-se inferir que nesta organização, sistemas de crenças são menos favorecidos. Este resultado não corrobora aos achados de Heinicke, Guenther e Widener (2016), os quais evidenciaram que em algumas organizações, sistemas de crenças representam um importante mecanismo de controle.

Apresenta-se no Quadro 3 as considerações dos sujeitos da pesquisa sobre os sistemas de fronteiras, ao serem questionados sobre como são estabelecidos os limites de atuação da organização, garantindo que as estratégias realizadas estejam dentro do domínio das atividades organizacionais (atividades, mercados, riscos) e como são estabelecidos os limites para guiar o comportamento dos indivíduos na organização.

\footnotetext{
Sujeito da

Pesquisa Considerações dos sujeitos da pesquisa sobre os sistemas de fronteiras

"Isso depende muito de como vai o mercado mundial, como nós exportamos bastante, a área comercial tem

Sujeito 1 uma previsão, então as vezes a gente vende na frente, como eu estava explicando primeiro, por que você tem que acompanhar desde os estoques mundiais, tudo". "Tem normas para que o funcionário trabalhe com a cooperativa".

Sujeito 2 "Não teria limites na exportação, sempre que abre oportunidades, está sempre em busca de novos mercados". "Os limites existem pelo RH, regras comportamentais repassadas pelo RH no momento da contratação".

Sujeito 3 "De mercado, o cara tem uma liberdade até onde pode ir, com controles da empresa". "Tem normas, conduta tudo dentro da empresa, para dar uma boa imagem para a cooperativa".

"Olha, sempre o limite onde a empresa pode chegar é desde que não vá ferir os princípios dela, que não vai

Sujeito 4 ferir missão, visão e os valores dela, nenhuma ação que venha ferir isso, você tem uma retaguarda por trás disso, não se pode fazer nada que venha a desvirtuar a tua companhia [...]". "Tem que estar treinando eles nos princípios $[\ldots]$..."

“Todos os gastos da divisão devem ser autorizados pelo respectivo gerente. Muitas vezes se extrapola o valor

Sujeito 5 em função da necessidade urgente de se fazer o negócio, mas isso, na primeira oportunidade, é comunicado para a diretoria". "Nós temos o código de ética".

“A gente tem um histórico do preço, tanto na compra como na venda, que é o que a gente se baseia nas decisões, quando esse preço é favorável, a gente toma iniciativas mais agressivas, quando é desfavorável a

Sujeito 6 gente fica um pouquinho mais na retaguarda, então baseado em alguns parâmetros a gente toma atitudes".

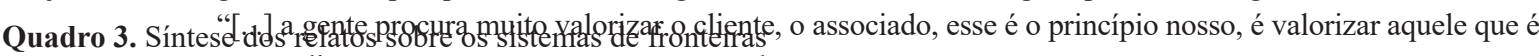
Fonte: Dados da pessgicliente, tanto na compra como na venda".
} 


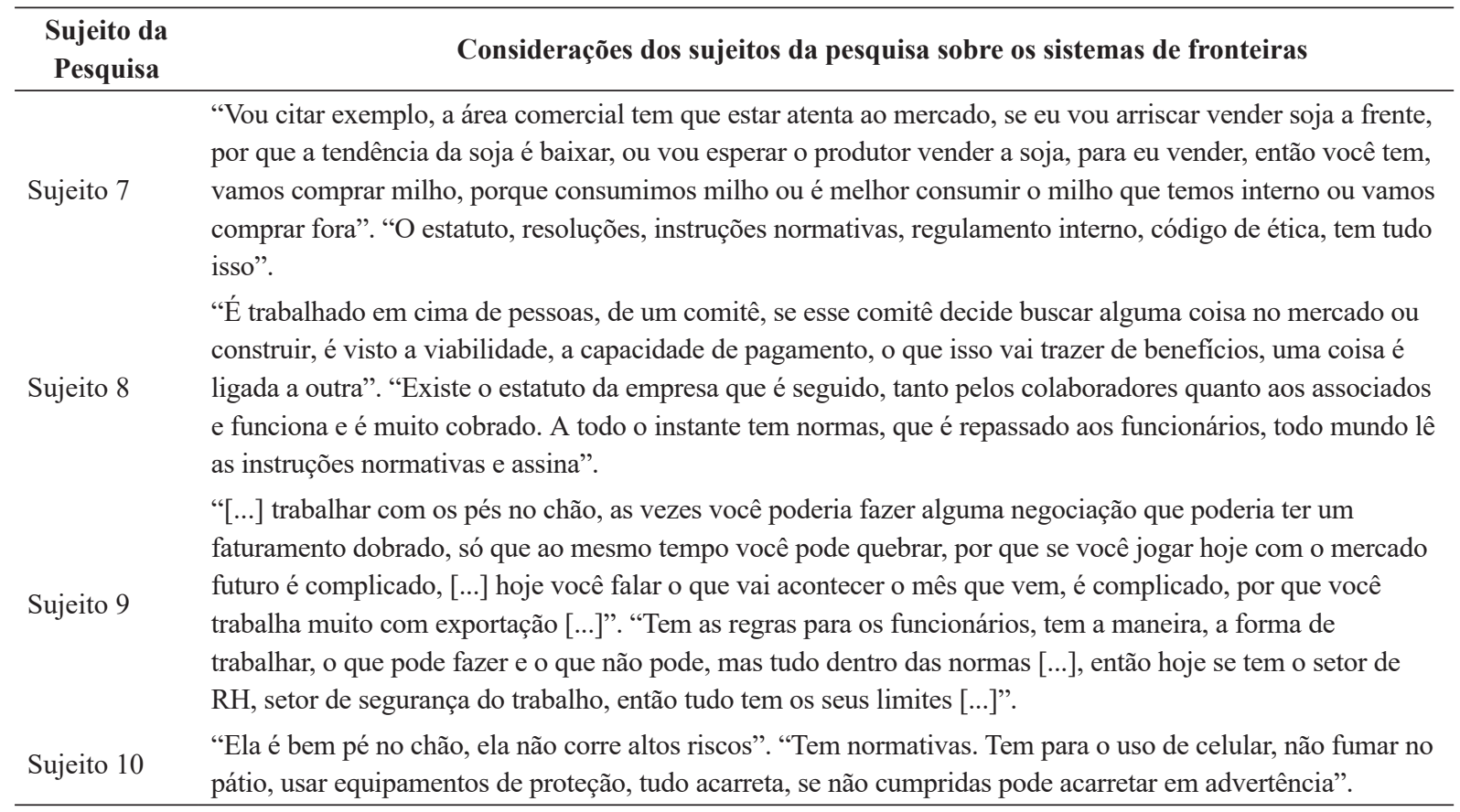

Quadro 3 (continuação). Síntese dos relatos sobre os sistemas de fronteiras

Fonte: Dados da pesquisa

Os limites de atuação da organização são estabelecidos de acordo com o mercado (preço do produto), exportações, princípios, missão, visão, valores, autorização de gastos, histórico de preços dos produtos, viabilidade e capacidade de pagamento. Ao referir-se as declarações de princípios, missão, visão, valores, mercado e exportações, este resultado vai ao encontro de Alves (2010), o qual identificou que os limites de atuação da organização em termos de atividades e mercados são definidos pelo planejamento estratégico e as declarações de visão e missão.

Diante dos limites de autorização de gastos, histórico de preço dos produtos, viabilidade e capacidade de pagamento, verifica-se que a organização utiliza como base o planejamento financeiro, orçamento, custos e fluxo de caixa, conforme entrevistas, documentos e observações.

Os limites comportamentais são estabelecidos por meio de normas, regras, princípios, os quais são visualizados no código de ética, estatuto, instruções normativas e regulamentos internos. No momento da contratação, o setor de Recursos Humanos repassa as regras comportamentais para o funcionário e também tem o setor de segurança do trabalho que emite as normas referentes a proteção do trabalhador.

Os resultados apresentados sobre o sistema de fronteira corroboram o estudo de Diehl (2006), de que a questão ética junto aos clientes e limites estratégicos são vinculados ao sistema de fronteira e com o estudo de Cruz (2014), que verificou que o sistema de fronteira, ao estabelecer limites para a ação dos funcionários, direciona-os para que as ações sejam desenvolvidas.

As evidências sugerem que os sistemas de fronteiras, tanto nos limites de atuação em termos de atividades e mercados, quanto nos limites comportamentais, estabelecidos por meio de normas, regras e princípios, têm como base e orientação os sistemas de crenças. Por mais que sistemas de crenças não são disseminados em toda a organização, estão relacionados com as atividades cotidianas da empresa. Ainda, sistemas de fronteiras são utilizados quando existe a necessidade de se estabelecer limites de atuação e comportamentais, não sendo utilizados constantemente, pois depois de estabelecidos os limites, se tornam regras, o que estimula a realização de novos estudos.

As considerações dos sujeitos da pesquisa sobre os sistemas de diagnóstico, ao serem questionados sobre como é monitorada e recompensada a realização de planos e metas, são apresentadas no Quadro 4.

A organização monitora a realização de planos e metas por meio dos seus custos, volume de produção, planejamento, orçamento, vendas, recebimento de grãos, cobranças, inadimplências. 


\begin{tabular}{|c|c|}
\hline $\begin{array}{l}\text { Sujeito da } \\
\text { Pesquisa }\end{array}$ & Considerações dos sujeitos da pesquisa sobre os sistemas de diagnóstico \\
\hline Sujeito 1 & $\begin{array}{l}\text { "Ele tem participação, agora para ele ter participação, ele precisa cumprir algumas metas aqui dentro. Então } \\
\text { no final de ano quando a gente faz a projeção de recebimento, faz todas as metas, do que a unidade precisa } \\
\text { receber, para essa unidade estar viabilizada [...]". }\end{array}$ \\
\hline Sujeito 2 & "Cada setor tem sua meta para ter participação no resultado". \\
\hline Sujeito 3 & $\begin{array}{l}\text { "Em cima de volume, custos, todas essas coisas têm que estar envolvido, por exemplo, na plataforma tem } \\
\text { uma meta por dia, tem que entregar tantos frangos com peso tal [...]". "Tem os planos de participação nos } \\
\text { resultados". }\end{array}$ \\
\hline Sujeito 4 & $\begin{array}{l}\text { "Então você cria metas individuais para esse setor, o setor que refina o peito, que elas têm que fazer } 8 \text { filés } \\
\text { de peito por minuto, você tem o setor de desossa, que tem que fazer um "x" número de peças por minuto". } \\
\text { "Recebem o salário normal e se atingiram a meta ganham uma variável". }\end{array}$ \\
\hline Sujeito 5 & "Nós fazemos o planejamento e orçamento". "É pelo PLR, pelas metas atingidas e do resultado alcançado". \\
\hline Sujeito 6 & $\begin{array}{l}\text { "Na área de insumo, a gente tem que vender durante o ano tantas mil toneladas, então essa é a meta, na parte } \\
\text { de grãos, receber tantas mil toneladas, então nós temos metas não por pessoas, temos metas por setor". "Nós } \\
\text { participamos do resultado anual". }\end{array}$ \\
\hline Sujeito 7 & $\begin{array}{l}\text { "Dentro do PLR, você tem as metas estipuladas no começo do ano, metas de recebimento e tal". "Existe as } \\
\text { metas gerais e algumas metas e bonificações em cima de alguma coisa específica". }\end{array}$ \\
\hline Sujeito 8 & $\begin{array}{l}\text { "[...] junto os funcionários e estabeleço metas para área técnica, tanto de vendas, estabeleço para a área } \\
\text { financeira, metas de cobrança, inadimplência". "Através da participação de resultado anual". }\end{array}$ \\
\hline Sujeito 9 & $\begin{array}{l}\text { "A gente controla, você tem a questão de vendas, recebimentos [...]". "Nós temos participação nos } \\
\text { resultados". }\end{array}$ \\
\hline Sujeito 10 & $\begin{array}{l}\text { "Por exemplo, metas de recebimento de grãos [...]" "[...] venda de insumos". "Participação nos resultados, } \\
\text { tanto para o associado como para o colaborador". }\end{array}$ \\
\hline
\end{tabular}

Quadro 4. Síntese dos relatos sobre os sistemas de diagnóstico

Fonte: Dados da pesquisa

Na realização dos planos e metas, os funcionários são recompensados por meio da Participação nos Lucros e Resultados (PLR).Além do PLR, a empresa trabalha com metas específicas, conforme o Sujeito 2 "Tem também recompensa quanto a assiduidade, no final do mês é recompensado com uma cesta básica". Identifica-se também nas considerações dos Sujeitos 4 e 7.

Você tem um salário e as atividades fundamentais, gargalos que a gente diz, se essa atividade não se realiza, vai ter uma infinidade de pessoas ociosas, se não refila o peito, vai ter uma infinidade de pessoas ociosas, porque não vão estar salgando, processando este produto para exportar, então estas pessoas nas atividades chaves elas recebem uma variável (Sujeito 4).

O próprio departamento técnico tem metas das multinacionais. Porque tem metas de multinacionais para vender insumos, então se atingir a meta ganha premiação [...], os prêmios são dados para as pessoas, o que representa um incentivo, claro que sempre repartindo. Existem as metas gerais e algumas metas e bonificações em relação a algo especifico (Sujeito 7).

No estudo de Alves (2010), o controle de metas, os orçamentos, os controles financeiros e as medidas não financeiras foram os principais controles utilizados na forma diagnóstica e sistemas de planejamento financeiro, avaliação financeira e controle de custos foram identificados na forma diagnóstica por Vasconcelos (2012), o que vai ao encontro do presente estudo. Ao contrário do estudo de Diehl (2006), no presente estudo o controle de diagnóstico não se apresentou frágil na empresa e as ações não são tomadas de forma reativa, como evidenciado nas entrevistas, documentos e observações.

As evidências sugerem que os controles de diagnóstico são utilizados constantemente na organização, fazendo parte da atividade cotidiana, tendo em vista que a empresa precisa monitorar suas atividades e resultados para alcançar os objetivos desejados. Assim, adota mecanismos que estimulem os membros da organização a se envolverem e se dedicarem a seu favor.

Apresenta-se no Quadro 5 as considerações dos sujeitos da pesquisa sobre os sistemas interativos, ao 
serem questionados sobre como os gestores se envolvem regularmente e pessoalmente nas atividades de decisão dos subordinados e como é estimulada a aprendizagem organizacional e a manifestação de novas ideias.

\begin{tabular}{|c|c|}
\hline $\begin{array}{l}\text { Sujeito da } \\
\text { Pesquisa }\end{array}$ & Considerações dos sujeitos da pesquisa sobre os sistemas interativos \\
\hline Sujeito 1 & $\begin{array}{l}\text { "Então toda a terça feira nós nos reunimos, os } 4 \text { diretores executivos, os } 4 \text { gerentes de divisão, que formam o } \\
\text { comitê de crédito, que nós chamamos, para tomar as decisões, analisar a semana e tomar novas decisões". "[...] } \\
\text { nós gostamos muito de ouvir os nossos funcionários [...]". }\end{array}$ \\
\hline Sujeito 2 & $\begin{array}{l}\text { "Nós não nos envolvemos diretamente, fica mais a cargo dos gerentes de divisão". "Através de reuniões, } \\
\text { conversas, treinamentos, cursos, pós-graduações dentro da cooperativa com um grupo de funcionários". }\end{array}$ \\
\hline Sujeito 3 & $\begin{array}{l}\text { "Tem os encarregados, a gente não está direto, senta com o encarregado do setor [...]”. A gente procura } \\
\text { conversar com ele [...]". "Você dá liberdade para eles estudar, buscar mais conhecimento, em cima disso, } \\
\text { que eles vão estudar, agregar conhecimento, que vem ajudar diretamente na empresa e a eles também, o } \\
\text { crescimento dentro da empresa". }\end{array}$ \\
\hline Sujeito 4 & $\begin{array}{l}\text { "[...] a gente trabalha com nível, vamos dizer assim, de colegiado, você consulta seus pares de setor, tem } \\
\text { os gerentes de divisão, a baixo de mim, tem os gerentes de departamento, que são três, cada gerente de } \\
\text { departamento tem as suas ramificações de supervisores". "Uma quarta feira por mês eu faço uma reunião com } \\
\text { a minha equipe e eu reconheço gente que faz a diferença, pessoas de dentro do processo que tiverem uma ideia } \\
\text { inovadora, que são pessoas diferenciadas, dedicadas, que buscam fazer alguma coisa". }\end{array}$ \\
\hline Sujeito 5 & $\begin{array}{l}\text { "Em cada área dessas eu tenho um gerente de departamento[...]". "Além disso tem o atendimento individual, } \\
\text { por que são situações diferentes de um departamento para outro". "Nós temos curso de pós-graduação in } \\
\text { company [...]". "Bom, nós temos os treinamentos constantemente, e a questão de novas ideias são apresentadas } \\
\text { nas reuniões que cada gerente de departamento faz com seus funcionários". }\end{array}$ \\
\hline Sujeito 6 & $\begin{array}{l}\text { "[...] a gente trabalha em conjunto [...]". "Todos têm oportunidade de aproveitar os cursos e toda vez que vem } \\
\text { palestra externa, a gente disponibiliza para que eles participam". "A gente tem que fazer com que o funcionário } \\
\text { participe, dê opiniões, para que ele não seja só um funcionário que recebe informações". }\end{array}$ \\
\hline Sujeito 7 & $\begin{array}{l}\text { “[...] na divisão operacional da cooperativa, que envolve os entrepostos, eu me relaciono com os gerentes de } \\
\text { entreposto e mais gerentes de manutenção, gerente de transporte, gerente da parte elétrica". "Nós temos hoje } \\
\text { funcionário fazendo pós-graduação [...]". "Treinamentos operacionais, a cooperativa traz o instrutor [...]". "A } \\
\text { gente estimula, pega ideias através de reuniões, de encontros". }\end{array}$ \\
\hline Sujeito 8 & $\begin{array}{l}\text { "A gente tem em cada unidade um assistente [...]". "Durante a semana eu tenho um dia marcado para ir nessas } \\
\text { unidades, então vai juntando os problemas, vai anotando, vai agendando e o dia que a gente vai lá resolve". } \\
\text { "Enche uma sala de gente e todo mundo dá uma ideia, monta um planejamento". "Tem campanhas e é avaliado } \\
\text { as melhores ideias". }\end{array}$ \\
\hline Sujeito 9 & $\begin{array}{l}\text { "Os entrepostos que eu administro, eu procuro sempre trabalhar com o grupo todo, sempre conversando [...]". } \\
\text { "[...] toda a ideia que vem é bem vinda e hoje pela diretoria também é a mesma situação [...]". }\end{array}$ \\
\hline Sujeito 10 & $\begin{array}{l}\text { "Eu gosto de ouvir a opinião do cooperado e do colaborador [...]". "A cooperativa ela investe em estudo, [..] } \\
\text { nós temos uma parceria, tem universidades da região que dão desconto para os funcionários da cooperativa, } \\
\text { tem uma ajuda de custo, ela incentiva na qualificação". }\end{array}$ \\
\hline
\end{tabular}

Quadro 5. Síntese dos relatos sobre os sistemas Interativos

Fonte: Dados da pesquisa

A partir do Quadro 5, verifica-se que os gestores da cooperativa se envolvem regularmente e pessoalmente nas atividades de decisão dos subordinados por meio de reuniões, realizadas nas terças-feiras de cada semana, com os diretores executivos e gerentes de divisão, em que cada gerente trás as contribuições dos funcionários do seu setor. Trimestralmente são realizadas reuniões com os gerentes de entrepostos. Cada gerente possui um líder responsável por setor específico, os quais informam as situações ao gerente principal e este leva nas reuniões trimestrais com os diretores executivos e gerentes de divisão. Além disso, ocorre o atendimento individual para cada colaborador.

A cooperativa investe em cursos, treinamentos, pós-graduações, incentiva o colaborador a estudar, pois entende que o conhecimento adquirido vem agregar nas atividades da empresa, além de contribuir para o alcance de melhores cargos na organização. No relatório anual, são descritas as atividades desenvolvidas para promover a aprendizagem organizacional.

A cooperativa possui, conforme nota explicativa, um fundo de reserva de assistência técnica, educacional 
e social, o qual destina-se a cobrir gastos com assistência técnica, educacional e social dos cooperados, seus familiares e os colaboradores. Ainda, os incentivos para a aprendizagem organizacional têm como base o planejamento financeiro e orçamento.

Verifica-se que os colaboradores têm liberdade para expor suas ideias e são estimulados para isto. A organização realiza campanhas para contribuir com ideias, em que as melhores ideias são premiadas. Na indústria, de acordo com o relato do Sujeito 4, tem-se o projeto "gente que faz a diferença", em que são reconhecidas as pessoas que se diferenciam no seu trabalho. Observou-se os e-mails enviados e recebidos para a confirmação da reunião em que são reconhecidos os funcionários diferenciais.

Estes resultados corroboram o estudo de Henri (2006), o qual demonstrou que os SCG contribuem para o processo de geração de conhecimento e colaboração. Conforme Diehl (2006) em seu estudo, o sistema de controle interativo apresentou-se bem desenvolvido, o que evidencia-se também no presente estudo.

O uso dos controles interativos verificados nas entrevistas, documentos e observações vão ao encontro do estudo de Bonner, Ruekert e Walker (2002), os quais demonstraram que a criatividade é utilizada de forma plena quando há flexibilidade na atividade desempenhada, o que foi evidenciado neste estudo, com os sistemas interativos que impulsionam o surgimento de novas ideias. Cruz (2014) constatou que empresas que buscam inovar precisam da participação de todos os membros da organização, o que também foi evidenciado nos resultados apresentados.

Diante destes resultados, infere-se que da mesma forma que sistemas de diagnóstico fazem parte do cotidiano da organização, sistemas interativos também são utilizados constantemente na organização objeto do estudo. Os gestores estão envolvidos diariamente com os colaboradores e é incentivado a aprendizagem organizacional e o surgimento de novas ideias. Isto faz com que os funcionários contribuam com a gestão da empresa, direcionado ao alcance de seus objetivos.

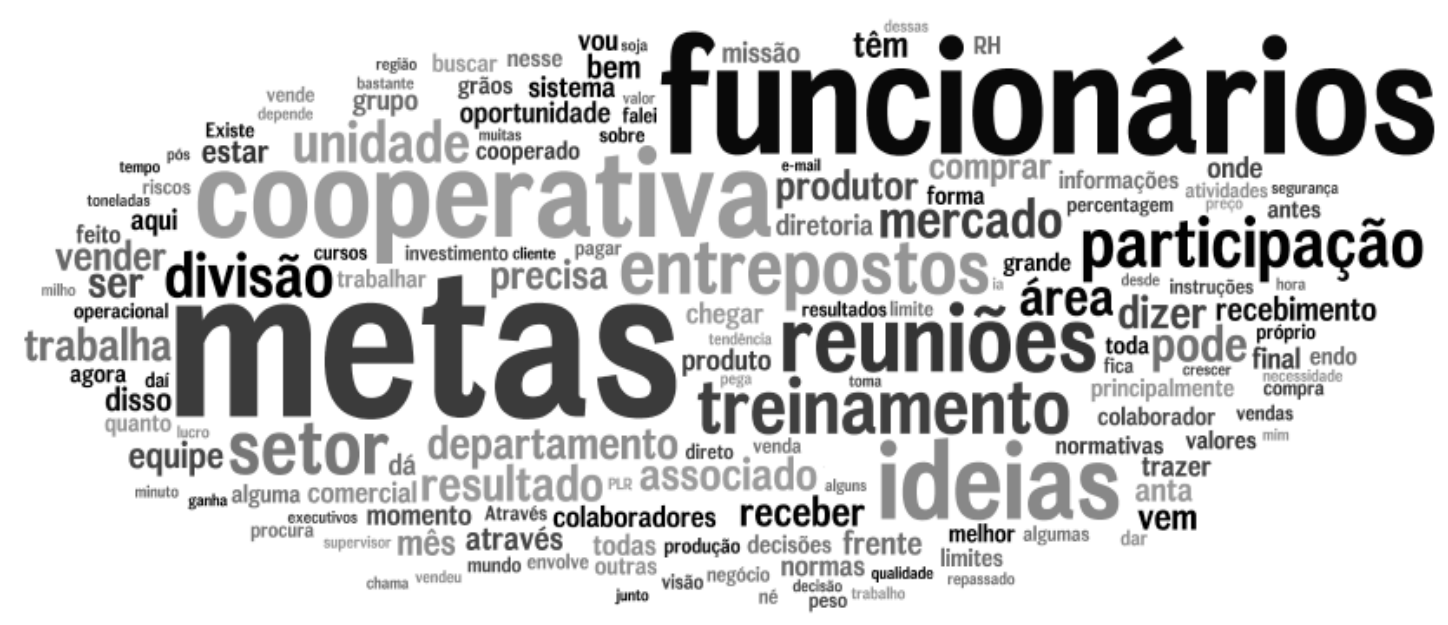

Figura 1. Nuvem de palavras das alavancas de controle

Fonte: Dados da pesquisa

As palavras mencionadas com maior frequência na entrevista referente aos sistemas de controle foram metas, funcionários, cooperativa, reuniões, setor, participação, ideias, treinamento, resultado, mercado, unidade, entrepostos e divisão. Estas palavras demonstram ênfase nos sistemas de controle de diagnóstico (metas, resultado, unidade, entrepostos, divisão e setor) e sistemas de controle interativo (participação, ideias, funcionários, reuniões e treinamento).

Estes resultados corroboram o estudo de Oyadomari (2008), o qual identificou que o uso interativo está relacionado com a aprendizagem organizacional, inovação e orientação para o mercado e que o sistema de diagnóstico é importante para a gestão da empresa e não desestimula a aprendizagem organizacional, inovação e orientação para o mercado.

Os resultados apresentados sugerem que sistemas de diagnóstico e sistemas interativos são os de maior utilização na organização, tendo em vista que estes são utilizados constantemente e fazem parte do dia a dia da 
organização objeto do estudo. Enquanto que os sistemas de crenças, por mais que estejam associados as atividades organizacionais, não se encontram disseminados em toda a organização, e, sistemas de fronteiras são utilizados eventualmente, quando há a necessidade de se estabelecer limites de atuação e comportamentais. Depois de estabelecidos os limites, estes seguem como regras institucionalizadas. Por tais motivos, sistemas de crenças e de fronteiras não se apresentaram evidentes. Por mais que alguns sistemas tenham se mostrado mais evidentes que outros, percebe-se que há uma composição das quatro alavancas de controle, o que vai ao encontro dos resultados de Kruis, Speklé e Widener (2016), os quais constataram nas organizações pesquisadas, uma solução estável composta por quatro padrões de controle.

\section{CONSIDERAÇÕES FINAIS}

O objetivo do estudo foi verificar como as alavancas de controle de Simons (1995) são utilizadas na gestão de uma Cooperativa Agroindustrial. Para tanto, desenvolveu-se uma pesquisa descritiva, estudo de caso e qualitativa. O objeto de estudo compreendeu uma Cooperativa Agroindustrial. Para a coleta de dados utilizou-se de entrevistas, documentos e observação. As evidências sugerem que as crenças não são disseminadas de forma clara na organização em estudo, necessitando ser melhorada. Isto estimula a realização de novos estudos, com o intuito de compreender como ocorre a utilização dos sistemas de crenças em outras empresas, bem como identificar se estes encontram-se institucionalizados. Diante desta constatação, pode-se inferir que nesta organização, sistemas de crenças são menos favorecidos.

Os resultados demonstraram que os sistemas de fronteiras, tanto nos limites de atuação em termos de atividades e mercados, quanto nos limites comportamentais, estabelecidos por meio de normas, regras e princípios, têm como base e orientação os sistemas de crenças. Por mais que sistemas de crenças não são disseminados em toda a organização, estão relacionados com as atividades cotidianas da cooperativa. Ainda, na cooperativa, sistemas de fronteiras são utilizados quando existe a necessidade de se estabelecer limites de atuação e comportamentais, não sendo utilizados constantemente, pois depois de estabelecidos os limites, se tornam regras, o que estimula a realização de novos estudos.

As evidências sugerem que os controles de diagnóstico são utilizados constantemente na organização, fazendo parte da atividade cotidiana, tendo em vista que a empresa precisa monitorar suas atividades e resultados para alcançar os objetivos desejados. Assim, adota mecanismos que estimulem os membros da organização a se envolverem e se dedicarem a seu favor. Infere-se que da mesma forma que sistemas de diagnóstico fazem parte do cotidiano da organização, sistemas interativos também são utilizados constantemente na organização objeto do estudo. Os gestores estão envolvidos diariamente com os colaboradores e é incentivado a aprendizagem organizacional e o surgimento de novas ideias. Isto faz com que os funcionários contribuam com a gestão da empresa, direcionado ao alcance de seus objetivos.

Diante dos resultados, verifica-se que sistemas de diagnóstico e sistemas interativos são os de maior utilização na organização, tendo em vista que estes são utilizados constantemente e fazem parte do dia a dia da organização objeto do estudo. Enquanto que os sistemas de crenças, por mais que estejam associados as atividades organizacionais, não se encontram disseminados em toda a organização, e, sistemas de fronteiras são utilizados eventualmente, quando há a necessidade de se estabelecer limites de atuação e comportamentais. Depois de estabelecidos os limites, estes seguem como regras institucionalizadas. Por tais motivos, sistemas de crenças e de fronteiras não se apresentaram evidentes. Constata-se assim que, a cooperativa investe no monitoramento das atividades e no envolvimento dos membros da organização, ficando menos evidente a disseminação das crenças, valores e de controles que fornecem restrições nas atividades.

Estes resultados sugerem que em cooperativas o uso das alavancas de controle pode ocorrer de forma diferenciada, comparativamente ao uso em outras organizações. As cooperativas por serem caracterizadas como entidades sem fins lucrativos, atendem a objetivos diferentes. Mesmo demandando o superávit para a viabilização de suas operações, sua principal finalidade é o progresso social de seus cooperados. Desta forma é possível se admitir a utilização com maior frequência de controles interativos e de diagnóstico.

Mesmo que estes resultados não possam ser generalizados, fornecem importantes evidências que estimulam a realização de novos estudos. Nesta perspectiva, escassas são as evidências sobre o uso dos SCG no contexto das cooperativas. Sugere-se para pesquisas futuras a investigação do uso dos Sistemas de Controle Gerencial em cooperativas e em outras empresas, tendo em vista que no Brasil este tema precisa ser mais explorado. 


\section{REFERÊNCIAS}

AGUIAR, Andson Braga de; FREZATTI, Fábio. Escolha da estrutura apropriada de um sistema de controle gerencial: uma proposta de análise. Revista de Educação e Pesquisa em Contabilidade (REPeC), v. 1, n. 3, p. 21-44, 2007.

ALVES, Adriano Bertoldo. Desenho e uso dos sistemas de controle gerencial e sua contribuição para a formação e implementação da estratégia organizacional. 2010. 112 f. Dissertação (Mestrado em Ciências Contábeis) - Departamento de Contabilidade e Atuária da Faculdade de Economia, Administração e Contabilidade, Universidade de São Paulo, São Paulo, 2010.

ALVES-MAZZOTTI, Alda Judith; GEWANDSZNAJDER, Fernando. O método nas ciências naturais e sociais: pesquisa quantitativa e qualitativa.2. ed. São Paulo: Pioneira, 1999. 203 p.

BIALOSKORSKI NETO, Sigismundo; NAGANO, Marcelo Seido; MORAES, Marcelo Botelho da Costa. Utilização de redes neurais artificiais para avaliação socioeconômica: uma aplicação em cooperativas. Revista de Administração da Universidade de São Paulo, v. 41, n. 1, 2006.

BISBE, Josep; OTLEY, David. The effects of the interactive use of management control systems on product innovation. Accounting, Organizations and Society, v. 29, n. 8, p. 709-737, 2004.

BONNER, Joseph M.; RUEKERT, Robert W.; WALKER, Orville C. Upper management control of new product development projects and project performance. Journal of Product Innovation Management, v. 19, n. 3, p. 233-245, 2002.

BRUINING, Hans; BONNET, Marcel; WRIGHT, Mike. Management control systems and strategy change in buyouts. Management Accounting Research, v. 15, n. 2, p. 155-177, 2004.

COLLIER, Paul M. Entrepreneurial control and the construction of a relevant accounting. Management AccountingResearch, v. 16, n. 3, p. 321-339, 2005.

CRUZ, Ana Paula Capuano da. Estilo de liderança, sistema de controle gerencial e inovação tecnológica: papel dos sistemas de crenças, interativo, diagnóstico e de restrições. 2014. 168 f. Tese (Doutorado em Ciências Contábeis) - Departamento de Contabilidade e Atuária da Faculdade de Economia, Administração e Contabilidade, Universidade de São Paulo, São Paulo, 2014.

CRUZ, Ana Paula Capuano; FREZATTI, Fábio; DE SOUZA BIDO, Diógenes. Estilo de Liderança, Controle Gerencial e Inovação: Papel das Alavancas de Controle. Revista de Administração Contemporânea, v. 19, n. 6, p. $772,2015$.

DIEHL, Carlos Alberto. Gestão Estratégica de Custos: identificando o alinhamento estratégico em uma empresa de segurança. Contabilidade Vista \& Revista, v. 17, n. 1, p. 69-97, 2006.

HEINICKE, Anja; GUENTHER, Thomas W.; WIDENER, Sally K. An examination of the relationship between the extent of a flexible culture and the levers of control system: The key role of beliefs control. Management Accounting Research, 2016.

HENRI, Jean-François. Management control systems and strategy: a resource-based perspective. Accounting, Organizations and Society, v. 31, n. 6, p. 529-558, 2006.

ISIDORO, Claudinei; FACCI, Nilson; ESPEJO, Marcia Maria Dos Santos Bortolocci; GARCIAS, Paulo Mello. A utilização de artefatos de contabilidade gerencial em cooperativas agropecuárias. Revista de Contabilidade da UFBA, v. 6, n. 2, p. 39-55, 2012.

KRUIS, Anne-Marie; SPEKLÉ, Roland F.; WIDENER, Sally K. The Levers of Control Framework: An exploratory analysis of balance. Management Accounting Research, 2015.

LANGFIELD-SMITH, Kim. Management control systems and strategy: a critical review. Accounting, Organizations and Society, v. 22, n. 2, p. 207-232, 1997.

LAVARDA, Carlos Eduardo Facin; PEREIRA, Alexandre Matos. Uso dos sistemas de controles de gestão nas diferentes fases do ciclo de vida organizacional. Revista Alcance, v. 19, n. 4, p. 497-518, 2012.

MARGINSON, David EW. Management control systems and their effects on strategy formation at middlemanagement levels: evidence from a UK organization. Strategic Management Journal, v. 23, n. 11, p. 1019-1031, 2002. 
NISIYAMA, Edelcio Koitiro; OYADOMARI, José Carlos Tiomatsu. Sistemas de controle gerencial e o processo de inovação. RAI: Revista de Administração e Inovação, v. 9, n. 1, p. 106-125, 2012.

ORGANIZAÇÃO DAS COOPERATIVAS BRASILEIRAS (OCB). História. Disponível em: <http://www.ocb. org.br/site/ramos/agropecuario_historia.asp>. Acesso em: 12 de março de 2015.

OTLEY, David T.; BERRY, Anthony J. Control, organisation and accounting. Accounting, Organizations and Society, v. 5, n. 2, p. 231-244, 1980.

OYADOMARI, José Carlos Tiomatsu. Uso do Sistema de Controle Gerencial e Desempenho: Um estudo em empresas brasileiras sob a ótica da VBR (Visão Baseada em Recursos). 2008. 130 f. Tese (Doutorado em Ciências Contábeis) - Departamento de Contabilidade e Atuária da Faculdade de Economia, Administração e Contabilidade, Universidade de São Paulo, São Paulo, 2008.

SIMONS, Robert. Strategic orientation and top management attention to control systems. Strategic Management Journal, v. 12, n. 1, p. 49-62, 1991.

SIMONS, Robert. The role of management control systems in creating competitive advantage: new perspectives. Accounting, Organizations and Society, v. 15, n. 1, p. 127-143, 1990.

SIMONS, Robert. Levers of control: how managers use innovative control systems to drive strategic renewal. Boston, Mass: Harvard Business School, 1995. 217 p.

SIMONS, Robert. Performance measurement \& control systems for implementing strategy. Upper Saddle River, N.J: Prentice Hall, 2000. 348 p.

VASCONCELOS, Inês Maria Marques. A utilização de sistemas de controlo de gestão nas pequenas e médias empresas de cariz tecnológico. 2012. 58 f.Dissertação (Mestrado em Contabilidade, Fiscalidade e Finanças Empresariais) - Instituto Superior de Economia e Gestão, Universidade Técnica de Lisboa, 2012.

WIDENER, Sally K. An empirical analysis of the levers of control framework. Accounting, Organizations and Society, v. 32, n. 7, p. 757-788, 2007.

ZHENG, Tong. Balancing the tensions between the control and innovative roles of management control systems: a case study of Chinese organization. 2012. 329 f. Theses (Doctoral of Business Administration) - University of Northumbria, 2012. 